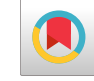

\title{
Long-Term Antithyroid Treatment in Pediatric and Juvenile Graves' Disease
}

\author{
Hossein Delshad ${ }^{1}$ and Miralireza Takyar ${ }^{1, *}$ \\ ${ }^{1}$ Endocrine Research Center, Research Institute for Endocrine Sciences, Shahid Beheshti University of Medical Sciences, Tehran, Iran \\ "Corresponding author: Endocrine Research Center, Research Institute for Endocrine Sciences, Shahid Beheshti University of Medical Sciences, Tehran, Iran. Email: \\ takyar@endocrine.ac.ir
}

Received 2020 June 20; Revised 2020 June 22; Accepted 2020 June 23.

\begin{abstract}
Context: Thyroid hormones can affect the development and function of the central nervous system and various other organs. As such, the pathologic excess of these hormones, known as thyrotoxicosis, can be the source of significant damage during childhood and adolescence. The objective of this study was to review the management of Graves' disease (GD) in the pediatric age group, especially concerning long-term antithyroid drug (ATD) treatment.

Evidence Acquisition: A thorough search of literature published from 1980 to 2019 was performed in PubMed only for English language literature. The following key terms were used: "Graves' disease, hyperthyroidism, thyrotoxicosis in children, thyrotoxicosis remission, thyrotoxicosis relapse, definite therapy, radioactive iodine, thyroidectomy, anti-thyroid drugs, propylthiouracil, methimazole, and carbimazole". We also did a thorough search in review articles, observational studies, open-label/controlled randomized/non-randomized trials, and meta-analyses, as well as the articles cited by textbooks, chapters, and review articles, which led us to locate older sources of information on the topic.

Results: More than $90 \%$ of thyrotoxicosis in the pediatric age group is attributable to GD. A host of strategies, including ATDs, radioiodine therapy, and surgery, are employed to treat this entity. However, there is still significant controversy regarding the most optimal strategy. Current evidence suggests that ATDs are the best initial treatment in pediatric patients with GD. Although ATDs are widely used, the duration of their administration is controversial and varies significantly between protocols. A major problem is the high relapse rate (up to 70\%), but extending the duration of such treatment could potentially bring the remission rate up to $88 \%$. Indications for using radioactive iodine treatment include the lack of remission following years of receiving ATDs, poor compliance, and the emergence of a major side effect. In pediatric patients aged five-years-old or younger who suffer from very large goiter, severe ophthalmopathy, and persistent hyperthyroidism, as well as those with the lack of response to or showing adverse effects of ATDs, it is advisable to consider total or near-total thyroidectomy.

Conclusions: Antithyroid drugs are the mainstay of treatment of juvenile GD, and long-term methimazole therapy increases the remission rate in pediatric GD.
\end{abstract}

Keywords: Thyrotoxicosis, Hyperthyroidism, Graves' Disease, Anti-Thyroid Medications, Radioactive Iodine, Thyroidectomy

\section{Context}

The term "thyrotoxicosis" is used to denote a surplus of thyroid hormones in circulation regardless of the source (1). Although the condition is not prevalent in childhood, it is a disorder with potentially grave consequences when afflicts a child (2). The most common cause of thyrotoxicosis in childhood is Graves' disease (GD), which is caused by an autoimmune process during which autoantibodies stimulate the thyrotropin (TSH) receptor. With a prevalence of $0.02 \%$ in childhood, GD in pediatric patients comprises less than $5 \%$ of the total number of people afflicted with this disease, while $2 \%$ of females and $0.2 \%$ of males in the adult population suffer from GD $(3,4)$. Other conditions that could cause transient thyrotoxicosis are using thyroid hormones acutely or for longer durations, acute or subacute thyroiditis, and chronic lymphocytic thyroiditis. Some rare causes of thyrotoxicosis include McCuneAlbright syndrome, mutations in the TSH receptor gene, both germline and gain-of-function, which could be seen in association with toxic nodules and diffuse hyperplasia, TSH-secreting pituitary tumors, and thyroid hormone resistance (Box 1).

Despite the availability of literature, there is still controversy regarding the optimal treatment of GD in the pediatric age group (5-7). Currently, antithyroid drugs (ATDs) 


\begin{tabular}{l} 
Box 1. Causes of Thyrotoxicosis in Children \\
\hline Causes of Thyrotoxicosis \\
\hline - Graves' disease \\
- Autoimmune neonatal hyperthyroidism (passage of maternal TRAbs across \\
the placenta) \\
- Thyroiditis \\
$\quad$ Subacute thyroiditis \\
$\quad$ Chronic lymphocytic thyroiditis (Hashimoto's disease) \\
- Exogenous causes \\
$\quad$ Exogenous thyroid hormone (acute or chronic) \\
Iodine-induced hyperthyroidism (iodine, radiocontrast agents, \\
$\quad$ amiodarone) \\
- Autonomous functioning nodules \\
Somatic activating mutation of Gs $\alpha$ (McCune-Albright syndrome) \\
Somatic activating mutation of the TSH receptor gene \\
Toxic adenoma \\
Hyperfunctioning papillary or follicular carcinoma \\
- Congenital activating mutations of the TSH receptor gene (hereditary or de \\
novo) (congenital hyperthyroidism) \\
- Selective pituitary resistance to thyroid hormones \\
- TSH-secreting pituitary tumors \\
\hline lating hormone \\
\hline
\end{tabular}

along with Radioactive Iodine (RAI) and subtotal or neartotal thyroidectomy are the modalities used more commonly in the treatment of GD. Each of these options is associated with certain complications, and no specific cure is available for this disease. Many guidelines are available for the treatment of hyperthyroidism (8-10). However, there is considerable variation among countries in terms of policies for the management of GD. Factors that can affect these strategies are age, patient preference, goiter size, disease severity, local resources, and tradition among physicians. Similar to other rare diseases, guidelines, and evidence-based strategies for managing GD in children are lacking $(4,11,12)$. Most patients are initially treated with ATDs; however, one aspect of using ATDs in the management of thyrotoxicosis in children is controversial: the literature is not conclusive regarding the length of time that these drugs should be continued. Due to the relatively long history of using ATDs in the past decades, a great deal is currently known about various aspects of these medications (13). Although most guidelines recommend using ATDs as the first-line treatment, the high rate of relapse (up to 70\%) after remission following the first course of therapy is a major challenge. Using ATDs for longer durations could potentially bring the remission rate up to $88 \%(14,15)$. This article aimed to review the overall management of juvenile GD with more emphasis on recent progress on long-term ATD therapy for pediatric age groups.

\section{Evidence Acquisition}

To acquire the relevant evidence for drafting this narrative review, a thorough search of literature published during a period from 1980 to 2019 was performed in PubMed only for English language literature. The following key terms were used for this search: "Graves' disease, hyperthyroidism, thyrotoxicosis in children, thyrotoxicosis remission, thyrotoxicosis relapse, definite therapy, radioactive iodine, thyroidectomy, anti-thyroid drugs, propylthiouracil, methimazole, and carbimazole". Observational studies, clinical trials, randomized controlled trials, metaanalyses, and reviews were all used to compile the literature to be assessed. To locate impactful older research, we used the list of references provided in book chapters and review articles.

\section{Results}

\subsection{General Management of Juvenile Graves' Disease}

There are no clear-cut, and simple therapies for GD, and the process of its management usually entails a complex decision that is not easy to make $(16,17)$. Currently, available management options do not lead to a cure and are limited due to the complications they could cause (18-21). Antithyroid drugs (methimazole $=$ MMI and propyl-thiouracil $=$ PTU), radioactive iodine (RAI), and surgery are the main treatment options for GD (22). Although the use of both ATDs and RAI is based on significant and long-standing experience, there is still no clear reasoning process through which a clinician can choose one or the other $(23,24)$. A high rate of relapse of hyperthyroidism upon discontinuation of the medication is a major challenge associated with treating GD patients with ATDs (25). On the contrary, ATD treatment is considerably more convenient compared to other options and has the advantage of not compromising thyroid function. Therefore, using this group of drugs at lower doses for the long-term could potentially be a viable alternative approach for the successful management of GD (26). Based on this notion, it has been suggested that instead of two-year cycles of treatment with ATDs, GD in children can be managed effectively with continuous methimazole (MMI), leading to gradual remission. It is also advisable to suggest low-dose long-term ATDs as a therapeutic option that could lead to euthyroidism and potentially remission (27). It should be mentioned that despite the mentioned benefits and potentially favorable compliance 
profile, ATDs carry the risk of some minor adverse events (such as rash, arthralgia, and gastric upset) and major but rare (less than 5\%) reactions of agranulocytosis and hepatotoxicity (26). Moreover, these medications, especially PTU, can lead to a certain type of ANCA-associated vasculitis when used for longer durations in pediatric populations (28). Therefore, PTU is not recommended for treating pediatric GD. Several studies with various designs in different settings have investigated the aspects of managing GD in pediatric populations using ATDs. Some research investigated the factors predicting remission with ATD treatment $(29,30)$. These studies, however, are few and far between with variable results. A study by Kaguelidou et al. found that one complete course of ATDs could incur the risk of relapse that was associated with ethnicity, age, and disease severity at diagnosis (29). Another study by Kourime et al. from Scotland (30) analyzed the data of 66 children (median age 11.8 years) who were diagnosed with GD between 1989 and 2012 and treated with ATDs. Twenty-seven patients stopped ATDs for second-line treatment, and one patient never stopped ATDs. Among those who had remission $(\mathrm{n}=35)$, the duration of therapy was $<3$ years in 12 patients and $>3$ years in 23 patients, and the follow-up was performed for a median of 11.8 (2.6 - 30.2) years. Seven of 12 children and 13 of 23 children had remission after ATD was given for $<3$ years and $>3$ years, respectively. Additionally, this study suggests that it would be extremely difficult to set a specific interval for discontinuing ATD because there is extreme variability in the time required for GD to go into remission. More recently, in an attempt to establish one such predictive factor that could potentially predict the early response to MMI, Hwang et al. (31) conducted a retrospective single-center study in South Korea in pediatric GD patients from 1993 to 2013 and concluded that following the initiation of treatment with MMI in children with GD, the levels of T3 normalized sooner in those with higher anti-microsomal antibody titers than in those with lower titers (2.53 months vs. 6.18 months, $\mathrm{P}<0.05$ ). Their results showed that age, sex, family history of thyroid diseases, thyroglobulin, thyroid-stimulating immunoglobulin, or antithyroglobulin antibody did not correlate with the time of normalization of T3, fT4, and TSH. The effect of age at the start of treatment with ATDs and how the dose and duration of ATDs should be adjusted accordingly have also been studied. The published reports indicated that pre-pubertal children would require different doses and longer durations of treatment to achieve remission $(14,15$, 32).

Although some aspects of ATDs use in treating GD in pediatric populations are investigated, as mentioned before, GD in children and adolescents is a rare disease, and many details of its management lack the acceptable levels of ev- idence. One such crucially important detail is the duration of ATD treatment as two recent meta-analyses strongly suggested that long-term treatment with ATDs, defined as a duration of treatment longer than 12 - 18 months, could lead to "cure" of GD hyperthyroidism safely $(33,34)$. In this context, "cure" is regarded as the "maintenance of health like it was before the disease process started" and is of importance in the setting of GD as it affects the lives of patients for considerably long periods. As such, long-term ATD treatment is not to be viewed only as a modification of a current therapy and should be considered an alternative treatment strategy. Although the above-mentioned studies focused on adult populations, it is equally important to be cognizant of the potentials of such treatment strategies for GD in pediatric populations, as these patients will have to live much longer periods of their lives with this disease and relevant treatments. This necessitates a closer analysis and review of studies investigating this aspect of ATD treatment in children and adolescents.

\subsection{Long-Term Antithyroid DrugTreatment in Children and Ado- lescents}

Prospective long-term clinical studies to assess remission rates in pediatric GD following short- and long-term ATD therapy are lacking, and little is known about longterm outcomes of such strategies. Only few studies are them up for a median duration of 10.4 (9.0 - 12.1) years. This study intended to find and treat children with GD who received three consecutive two-year courses of carbimazole treatment. The duration of remission of at least 18 months after one complete course of ATDs was chosen as the main outcome measure. In this study, there was an increase in the overall remission rates 18 months after discontinuing ATDs. The rates (95\% confidence intervals) after four, six, eight, and 10 years were 20\% (13\% - 26\%), 37\% (29\% - 45\%), $45 \%$ (35\% - 54\%), and 49\% (40\% - 57\%), respectively. Overall, the estimated rate of relapse of hyperthyroidism two years after finishing the first course of ATDs was 68\%. A few studies have reported over four years of ATD treatment in children and adolescents. In one study, Barrio et al. reported data of 20 children and adolescents with GD who received ATDs for as long as six years (36). All children were treated with ATDs as the first therapeutic option and were followed up for a mean duration of $13.8 \pm 5.5$ years. Low doses of ATDs led to long-term remission (mean treatment time 5.4 \pm 1.4 years) in $40 \%$ of patients in this study. None of the patients requiring high doses of ATDs to maintain euthyroidism achieved long-term remission and were treated with radioactive iodine and/or thyroidectomy. Later, Sato et al. studied 60 GD children and adolescents who received ATDs for a median of $5 \pm 2.1$ years after diagnosis (23). This study was designed to compare children and adolescents 
with GD who received propylthiouracil (group P) and those starting on and continuing MMI (group M) in terms of the efficacy of treatment and adverse reaction profiles in the initial phase of treatment and longer outcomes. In this study, T4 stayed normalized for a mean ( \pm SD) duration of $1.7 \pm 1.0$ months in group $M$ and $2.3 \pm 2.4$ in group $P$, and major adverse reactions were not observed. However, 25\% of the patients in group $\mathrm{M}$ and $31.9 \%$ of those in group P experienced minor adverse effects, but this difference was not statistically significant. Remission rates did not differ between group M (35.0\%), and group P (50.0\%), and the authors concluded that using PTU as an initial treatment in children and adolescents with GD may not be a feasible option. Yasuda et al. conducted a retrospective study to evaluate the correlation between MMI doses and adverse events, on the one hand, and the age of onset of less than 15 years, on the other hand, in 56 GD patients (24). The patients in this study received ATDs for a mean duration of 6.9 years and were followed up for 9.1 years. Besides, 11 male and 45 female patients with a median age at diagnosis of 11 years were recruited in the study, all of whom received ATDs as the initial treatment. Moreover, 52 patients received MMI at either low (20 patients) or high (32 patients) doses (< 0.7 vs. $\geq 0.7 \mathrm{mg} / \mathrm{kg} /$ day, respectively). The results showed that $20 \%$ of the patients in the lowdose group and $50 \%$ of those in the high-dose group experienced adverse events $(P=0.031)$, with neutropenia and rash reported in both groups. Azizi et al. assessed longterm MMI treatment by comparing the remission rates in GD patients after long-term and short-term therapy (37) by conducting a randomized, parallel-group trial between May 2000 and March 2017 in Tehran, which is considered an area of iodine sufficiency. They included 66 consecutive patients with untreated juvenile Graves' hyperthyroidism in their prospective study. All patients were treated with MMI for 18 to 24 months and then were randomly assigned to continue MMI (long-term group with 24 patients) or discontinue the medication (short-term group). The longterm group patients completed 96 to 120 months of MMI treatment. Both groups were followed up for 48 months following discontinuation of treatment. Hyperthyroidism was cured in $88 \%$ of long-term patients and $33 \%$ of shortterm patients four years after MMI withdrawal (Figure 1). Their results suggested that receiving MMI for durations of 96 to 120 months could be safe and effective for the treatment of juvenile GD. This was corroborated by a significantly higher (almost three times more) four-year cure rate of hyperthyroidism with long-term MMI compared to the short-term group.

The characteristics of studies with long-term ATD therapy in children and adolescents are summarized in Table 1. All patients in these four studies had a mean or me- dian duration of ATD treatment equal to or over 60 months and were euthyroid at the end of the study. Minor adverse events were reported in the first year by all of these studies. No major adverse events were reported after the first year of ATD administration. Azizi and Malboosbaf, in a systematic review and meta-analysis, tried to clarify the numerous aspects of long-term treatment with ATDs (33). In this meta-analysis, six studies were included reporting the data for long-term (> 24 months) ATD treatment in adults and non-adults. Long-term ATD treatment induced a remission rate of 57\%. A subgroup analysis demonstrated that the remission rate was higher in adults than in non-adults (61\% vs. $53 \%$ ) associated with low rates of complications. The annual remission rate for each year of treatment was $16 \%$, which was higher in adults than in non-adults (19\% vs. $14 \%$ ). Long-term ATD treatment has few adverse events, the majority of which occur in the first months of treatment and are more frequent in higher doses and children. Therefore, at the end of a custom course of ATD treatment (12 18 months), the "hazard window" is passed, and afterward, the adverse events will be very rare. Therefore, the patient can be kept euthyroid safely on low-dose ATDs.

\subsection{Concluding Remarks}

Replacing a disease like Graves' hyperthyroidism with another disease, i.e., hypothyroidism, as happens with ablative therapies, is not a "cure". The optimal therapeutic solution for GD, given the long duration of the disease, especially in children and adolescents, is to "cure" this disease, defined as the "maintenance of health like it was before the disease", rather than terminating hyperthyroidism by inciting a severe state of hypothyroidism. Currently, ATDs are the treatment of choice as the initial intervention for GD in the pediatric age group with ablative therapies reserved for those with poor compliance with or resistance to ATDs, or showing adverse effects while on ATDs. However, the main drawback of ATD therapy is the relatively high rates of relapse (close to 70\%) in pediatric GD. Recent evidence suggests that longer-term treatment with ATDs could lead to far improved results in the pediatric age group with an acceptable safety profile. Therefore, long-term ATD treatment is to be considered not as just a modification of current therapy, rather as an alternative treatment strategy. In such a paradigm, future prospective studies are encouraged with comprehensive designs in pediatric age groups.

Considering the low frequency of side effects in patients on lower doses of ATDs and the fact that euthyroid patients on ATDs have fewer complaints than those taking levothyroxine, we support the recommendation of MMI treatment for all juvenile hyperthyroid patients. In addition, continuous MMI administration 


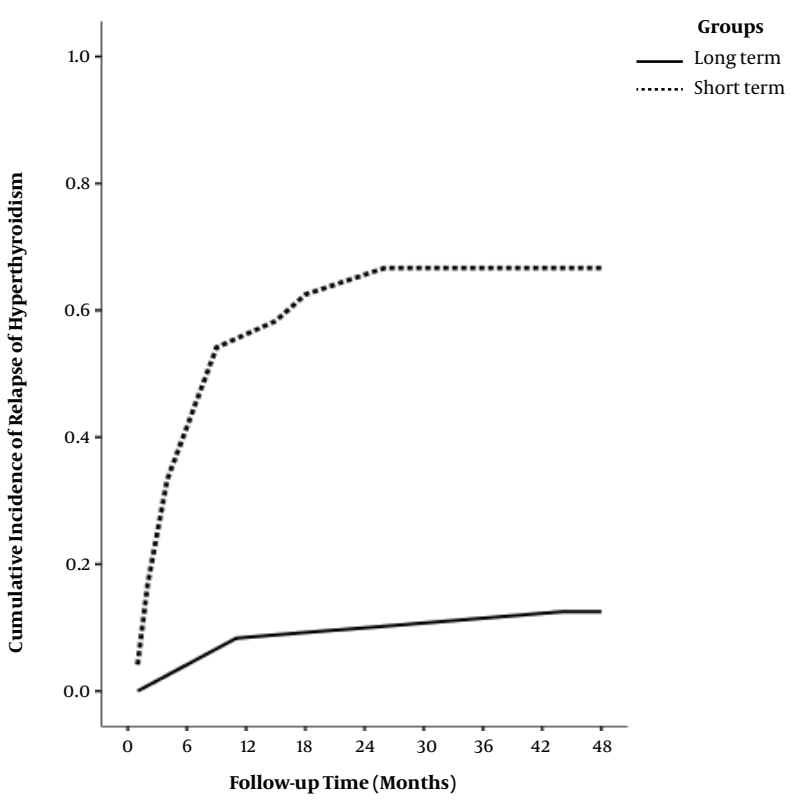

$\begin{array}{rcccccccc}\text { Month } & \mathbf{6} & \mathbf{1 2} & \mathbf{1 8} & \mathbf{2 4} & \mathbf{3 0} & \mathbf{3 6} & \mathbf{4 2} & \mathbf{4 8} \\ \begin{array}{r}\text { Long-term Group } \\ (\mathrm{n}=24)\end{array} & 4(1) & 8(2) & 8(2) & 8(2) & 8(2) & 8(2) & 8(2) & 16(3) \\ \begin{array}{r}\text { Conventional } \\ \text { Group }(\mathrm{n}=24)\end{array} & 42(10) & 54(13) & 63(15) & 63(15) & 67(16) & 67(16) & 67(16) & 67(16)\end{array}$

Figure 1. Remission rate following methimazole discontinuation in long-term and short-term groups. In adolescents with Graves' disease, the cure of hyperthyroidism occurred in $92 \%$ and $88 \%$ of those treated for $60-100$ months (long-term) and $46 \%$ and $33 \%$ of those treated for a median of 22 months, following one and four years of methimazole withdrawal, respectively. Adapted from (37).

\begin{tabular}{|c|c|c|c|c|c|c|c|c|}
\hline $\begin{array}{l}\text { First Author } \\
\text { (Ref. No) }\end{array}$ & Location & $\begin{array}{c}\text { Publication } \\
\text { Year }\end{array}$ & Study Design & Method & $\begin{array}{l}\text { Number of } \\
\text { Participants } \\
\text { (Start-End) }\end{array}$ & Age Range (Y) & $\begin{array}{c}\text { Mean } \\
\text { Duration of } \\
\text { Treatment } \\
\text { (Months) }\end{array}$ & $\begin{array}{c}\text { Adverse } \\
\text { Events }\end{array}$ \\
\hline Barrio R (36) & Spain & 2005 & Retrospective & Long-term ATD & $20-20$ & $8-18$ & 60 & $\begin{array}{c}\text { Minor adverse } \\
\text { events }\end{array}$ \\
\hline Sato H (23) & Japan & 2011 & Retrospective & $\begin{array}{l}\text { Long-term ATD } \\
\text { (MMI vs. PTU) }\end{array}$ & $60-60$ & 9-16 & 60 & $\begin{array}{l}\text { Minor adverse } \\
\text { events }\end{array}$ \\
\hline Yasuda K (24) & Japan & 2017 & Retrospective & $\begin{array}{l}\text { Long-term MMI } \\
\text { (Low dose vs. } \\
\text { high dose) }\end{array}$ & $52-36$ & $2-15$ & 8.9 & $\begin{array}{l}80 \% \text { of adverse } \\
\text { events within } \\
\text { the first three } \\
\text { months. One } \\
\text { neutropenia at } \\
11.5 \text { years }\end{array}$ \\
\hline
\end{tabular}

Abbreviations: ATD, antithyroid drug; MMI, methimazole; PTU, propylthiouracil.

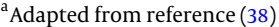

can cause fewer events of subclinical hypo- and hyperthyroidism and dyslipidemia, and patients on MMI therapy have better neuropsychological test results compared to levothyroxine-treated patients with radioiodine-induced 
hypothyroidism. Long-term MMI treatment is a safe and effective treatment option for juvenile Graves' disease, leading to higher remission rates than in the standard treatment.

\section{Footnotes}

Authors' Contribution: Both authors contributed to the conception, drafting, and editing of the manuscript.

Conflict of Interests: There are no conflicts of interest by any of the authors.

Funding/Support: The Research Institute for Endocrine Sciences, Shahid Beheshti University of Medical Sciences, Tehran, Iran, funded the study.

\section{References}

1. De Leo S, Lee SY, Braverman LE. Hyperthyroidism. The Lancet. 2016;388(10047):906-18. doi: 10.1016/s0140-6736(16)00278-6.

2. Lavard L, Ranlov I, Perrild H, Andersen O, Jacobsen BB. Incidence of juvenile thyrotoxicosis in Denmark, 1982-1988. A nationwide study. Eur J Endocrinol. 1994;130(6):565-8. doi: 10.1530/eje.0.1300565. [PubMed: 8205255].

3. Kliegman RM, Stanton BF, St Geme JW, Schor NF, Behrman RE, Nelson WE. Nelson textbook of pediatrics. Philadelphia: Elsevier; 2016.

4. Rodolph CD, Rodulph AM. Rodulph's pediatrics. 22nd ed. New York: McGraw Hill Medical; 2011. 2488 p.

5. Weetman AP. Graves' disease. N Engl J Med. 2000;343(17):1236-48. doi: 10.1056/NEJM200010263431707. [PubMed: 11071676].

6. Cooper DS. Hyperthyroidism. The Lancet. 2003;362(9382):459-68. doi: 10.1016/s0140-6736(03)14073-1.

7. Rivkees SA. Pediatric Graves' disease: controversies in management. Horm Res Paediatr. 2010;74(5):305-11. doi: 10.1159/000320028. [PubMed: 20924158].

8. Rivkees SA. Controversies in the management of Graves' disease in children. J Endocrinol Invest. 2016;39(11):1247-57. doi: 10.1007/s40618016-0477-x. [PubMed: 27153850].

9. Rivkees SA. Pediatric Graves' disease: management in the postpropylthiouracil Era. Int J Pediatr Endocrinol. 2014;2014(1):10. doi: 10.1186/1687-9856-2014-10. [PubMed: 25089127]. [PubMed Central: PMC4118280].

10. Cooper DS. Antithyroid Drugs for the Treatment of Hyperthyroidism Caused by Graves' Disease. Endocrinology and Metabolism Clinics of North America. 1998;27(1):225-47. doi:10.1016/s0889-8529(05)70308-x.

11. Vanderpump MP, Ahlquist JA, Franklyn JA, Clayton RN. Consensus statement for good practice and audit measures in the management of hypothyroidism and hyperthyroidism. The Research Unit of the Royal College of Physicians of London, the Endocrinology and Diabetes Committee of the Royal College of Physicians of London, and the Society for Endocrinology. BMJ. 1996;313(7056):539-44. doi: 10.1136/bmj.313.7056.539. [PubMed: 8789985]. [PubMed Central: PMC2351923].

12. Singer PA. Treatment guidelines for patients with hyperthyroidism and hypothyroidism. Standards of Care Committee, American Thyroid Association. JAMA: The Journal of the American Medical Association. 1995;273(10):808-12. doi:10.1001/jama.273.10.808.

13. Baskin HJ, Cobin RH, Duick DS, Gharib H, Guttler RB, Kaplan MM, et al. American Association of Clinical Endocrinologists Medical Guidelines for Clinical Practice for the Evaluation and Treatment of Hyperthyroidism and Hypothyroidism. Endocr Pract. 2002;8(6):457-69. doi: 10.4158/1934-2403-8.6.457. [PubMed: 27762623].
14. Cooper DS. Antithyroid drugs. N Engl J Med. 2005;352(9):905-17. doi 10.1056/NEJMra042972. [PubMed: 15745981].

15. Weetman AP. Graves' hyperthyroidism: how long should antithyroid drug therapy be continued to achieve remission? Nat Clin Pract Endocrinol Metab. 2006;2(1):2-3. doi: 10.1038/ncpendmet0068. [PubMed: 16932244].

16. Mazza E, Carlini M, Flecchia D, Blatto A, Zuccarini O, Gamba S, et al Long-term follow-up of patients with hyperthyroidism due to Graves' disease treated with methimazole. Comparison of usual treatment schedule with drug discontinuation vs continuous treatment with low methimazole doses: a retrospective study. J Endocrinol Invest. 2008;31(10):866-72. doi:10.1007/BF03346433. [PubMed: 19092290].

17. Marino M, Latrofa F, Menconi F, Chiovato L, Vitti P. An update on the medical treatment of Graves' hyperthyroidism. J Endocrinol Invest. 2014;37(11):1041-8. doi: 10.1007/s40618-014-0136-z. [PubMed: 25185644].

18. Rivkees SA, Dinauer C. An optimal treatment for pediatric Graves' disease is radioiodine. J Clin Endocrinol Metab. 2007;92(3):797-800. doi: 10.1210/jc.2006-1239. [PubMed: 17341574].

19. Lee JA, Grumbach MM, Clark OH. The optimal treatment for pediatric Graves' disease is surgery. J Clin Endocrinol Metab. 2007;92(3):801-3. doi: 10.1210/jc.2006-1238. [PubMed: 17341575].

20. Nakamura H, Noh JY, Itoh K, Fukata S, Miyauchi A, Hamada N. Comparison of methimazole and propylthiouracil in patients with hyperthyroidism caused by Graves' disease. J Clin Endocrinol Metab. 2007;92(6):2157-62. doi: 10.1210/jc.2006-2135. [PubMed:17389704].

21. Rivkees SA, Szarfman A. Dissimilar hepatotoxicity profiles of propylthiouracil and methimazole in children. J Clin Endocrinol Metab. 2010;95(7):3260-7. doi:10.1210/jc.2009-2546. [PubMed: 20427502].

22. Brito JP, Schilz S, Singh Ospina N, Rodriguez-Gutierrez R, Maraka $S$, Sangaralingham LR, et al. Antithyroid Drugs-The Most Common Treatment for Graves' Disease in the United States: A Nationwide Population-Based Study. Thyroid. 2016;26(8):1144-5. doi 10.1089/thy.2016.0222. [PubMed: 27267495].

23. Sato H, Minagawa M, Sasaki N, Sugihara S, Kazukawa I, Minamitani $\mathrm{K}$, et al. Comparison of methimazole and propylthiouracil in the management of children and adolescents with Graves' disease: efficacy and adverse reactions during initial treatment and longterm outcome. J Pediatr Endocrinol Metab. 2011;24(5-6):257-63. doi: 10.1515/jpem.2011.194. [PubMed: 21823520].

24. Yasuda K, Miyoshi Y, Tachibana M, Namba N, Miki K, Nakata Y, et al Relationship between dose of antithyroid drugs and adverse events in pediatric patients with Graves' disease. Clin Pediatr Endocrinol. 2017;26(1):1-7. doi: 10.1297/cpe.26.1. [PubMed: 28203042]. [PubMed Central: PMC5295245].

25. Anagnostis P, Adamidou F, Polyzos SA, Katergari S, Karathanasi E, Zouli C, et al. Predictors of long-term remission in patients with Graves' disease: a single center experience. Endocrine. 2013;44(2):44853. doi: 10.1007/s12020-013-9895-0. [PubMed: 23397523].

26. Orgiazzi J. Should Protracted Treatment with Antithyroid Drug (ATD) Be Considered as A Routine Strategy in Patients with Graves' Disease Who Had a Relapse after a First Course of ATD? Clinical Thyroidology. 2015;27(11):302-5. doi:10.1089/ct.2015;27.302-305.

27. Leger J, Carel JC. Management of endocrine disease: Arguments for the prolonged use of antithyroid drugs in children with Graves' disease. Eur J Endocrinol. 2017;177(2):R59-67. doi: 10.1530/EJE-16-0938. [PubMed: 28381452].

28. Balavoine AS, Glinoer D, Dubucquoi S, Wemeau JL. Antineutrophil Cy toplasmic Antibody-Positive Small-Vessel Vasculitis Associated with Antithyroid Drug Therapy: How Significant Is the Clinical Problem? Thyroid.2015;25(12):1273-81. doi:10.1089/thy.2014.0603. [PubMed: 26414658].

29. Kaguelidou F, Alberti C, Castanet M, Guitteny MA, Czernichow P, Leger J, et al. Predictors of autoimmune hyperthyroidism relapse in children after discontinuation of antithyroid drug treatment. $J$ 
Clin Endocrinol Metab. 2008;93(10):3817-26. doi: 10.1210/jc.2008-0842. [PubMed: 18628515].

30. Kourime M, McGowan S, Al Towati M, Ahmed SF, Stewart G Williamson S, et al. Long-term outcome of thyrotoxicosis in childhood and adolescence in the west of Scotland: the case for long-term antithyroid treatment and the importance of initial counselling. Archives of disease in childhood. 2018;103(7):637-42.

31. Hwang SM, Kim MS, Lee DY. Predictive factors for early response to methimazole in children and adolescents with Graves disease: a singleinstitute study between 1993 and 2013. Ann Pediatr Endocrinol Metab. 2016;21(2):70-4. doi: 10.6065/apem.2016.21.2.70. [PubMed: 27462582] [PubMed Central: PMC4960017].

32. Allahabadia A, Daykin J, Holder RL, Sheppard MC, Gough SC, Franklyn JA. Age and gender predict the outcome of treatment for Graves' hyperthyroidism. J Clin Endocrinol Metab. 2000;85(3):1038-42. doi 10.1210/jcem.85.3.6430. [PubMed: 10720036].

33. Azizi F, Malboosbaf R. Long-Term Antithyroid Drug Treatment: A Systematic Review and Meta-Analysis. Thyroid. 2017;27(10):1223-31. doi 10.1089/thy.2016.0652. [PubMed: 28699478].
34. Azizi F, Malboosbaf R. Safety of long-term antithyroid drug treatment? A systematic review. J Endocrinol Invest. 2019;42(11):1273-83. doi: 10.1007/s40618-019-01054-1. [PubMed: 31134536].

35. Leger J, Gelwane G, Kaguelidou F, Benmerad M, Alberti C, French Childhood Graves' Disease Study G. Positive impact of long-term antithyroid drug treatment on the outcome of children with Graves' disease: national long-term cohort study. J Clin Endocrinol Metab. 2012;97(1):110-9. doi: 10.1210/jc.2011-1944. [PubMed: 22031519].

36. Barrio R, Lopez-Capape M, Martinez-Badas I, Carrillo A, Moreno JC, Alonso M. Graves' disease in children and adolescents: response to long-term treatment. Acta Paediatr. 2005;94(11):1583-9. doi: 10.1080/08035250500252872. [PubMed: 16303698].

37. Azizi F, Takyar M, Madreseh E, Amouzegar A. Long-term Methimazole Therapy in Juvenile Graves' Disease: A Randomized Trial. Pediatrics. 2019;143(5). doi: 10.1542/peds.2018-3034. [PubMed: 31040197].

38. Azizi F. Long-term treatment of hyperthyroidism with antithyroid drugs: 35 years of personal clinical experience. Thyroid. 2020;In Press. doi: $10.1089 /$ thy.2019.0814 